\title{
Apabetalone and hospitalization for heart failure in patients following an acute coronary syndrome: a prespecified analysis of the BETonMACE study
}

Stephen J. Nicholls ${ }^{*}$, Gregory G. Schwartz ${ }^{2}$, Kevin A. Buhr ${ }^{3}$, Henry N. Ginsberg ${ }^{4}$, Jan O. Johansson ${ }^{5}$, Kamyar Kalantar-Zadeh ${ }^{6}$, Ewelina Kulikowski ${ }^{5}$, Peter P. Toth ${ }^{7,8}$, Norman Wong ${ }^{5}$, Michael Sweeney ${ }^{5}$ and Kausik K. Ray ${ }^{9}$ on behalf of the BETonMACE Investigators

\begin{abstract}
Background: Patients with diabetes and acute coronary syndrome (ACS) are at high risk for subsequent heart failure. Apabetalone is a selective inhibitor of bromodomain and extra-terminal (BET) proteins, epigenetic regulators of gene expression. Preclinical data suggest that apabetalone exerts favorable effects on pathways related to myocardial structure and function and therefore could impact subsequent heart failure events. The effect of apabetalone on heart failure events after an ACS is not currently known.

Methods: The phase 3 BETonMACE trial was a double-blind, randomized comparison of apabetalone versus placebo on the incidence of major adverse cardiovascular events (MACE) in 2425 patients with a recent ACS and diabetes. This prespecified secondary analysis investigated the impact of apabetalone on hospitalization for congestive heart failure, not previously studied.
\end{abstract}

Results: Patients (age 62 years, 74.4\% males, 90\% high-intensity statin use, LDL-C $70.3 \mathrm{mg} / \mathrm{dL}, \mathrm{HDL}-\mathrm{C} 33.3 \mathrm{mg} / \mathrm{dL}$ and $\mathrm{HbA1c} 7.3 \%$ ) were followed for an average 26 months. Apabetalone treated patients experienced the nominal finding of a lower rate of first hospitalization for heart failure ( $2.4 \% \mathrm{vs} .4 .0 \%, \mathrm{HR} 0.59$ [95\%Cl $0.38-0.94], \mathrm{P}=0.03$ ), total number of hospitalizations for heart failure ( $35 \mathrm{vs} .70, \mathrm{HR} 0.47[95 \% \mathrm{Cl} 0.27-0.83], \mathrm{P}=0.01$ ) and the combination of cardiovascular death or hospitalization for heart failure (5.7\% vs. 7.8\%, HR 0.72 [95\% Cl 0.53-0.98], P=0.04).

Conclusion: Apabetalone treatment was associated with fewer hospitalizations for heart failure in patients with type 2 diabetes and recent ACS. Future studies are warranted to define the potential for BET inhibition with apabetalone to prevent heart failure in patients with diabetes and ACS.

Keywords: BET inhibitors, Acute coronary syndrome, Diabetes, Heart failure, Clinical trial, Cardiovascular disease, Epigenetics, Atherosclerosis

*Correspondence: stephen.nicholls@monash.edu

1 Monash Cardiovascular Research Centre, Monash University, 246 Clayton Road, Clayton, VIC 3168, Australia

Full list of author information is available at the end of the article

\section{Introduction}

Despite current evidence-based treatment, patients with diabetes and acute coronary syndromes (ACS) have a high risk of experiencing subsequent cardiovascular events, including those related to congestive heart failure [1]. Observational studies have reported that congestive

(c) The Author(s) 2021. This article is licensed under a Creative Commons Attribution 4.0 International License, which permits use, sharing, adaptation, distribution and reproduction in any medium or format, as long as you give appropriate credit to the original author(s) and the source, provide a link to the Creative Commons licence, and indicate if changes were made. The images or other third party material in this article are included in the article's Creative Commons licence, unless indicated otherwise in a credit line to the material. If material is not included in the article's Creative Commons licence and your intended use is not permitted by statutory regulation or exceeds the permitted use, you will need to obtain permission directly from the copyright holder. To view a copy of this licence, visit http://creativecommons.org/licenses/by/4.0/. The Creative Commons Public Domain Dedication waiver (http://creativecommons.org/publicdomain/zero/1.0/) applies to the data made available in this article, unless otherwise stated in a credit line to the data. 
heart failure develops in up to $25 \%$ of patients who have experienced an ACS within the preceding 12 months, particularly among those with diabetes $[2,3]$. The clinical significance of this complication is evidenced by frequent hospitalizations, increased mortality and a substantial increase in the use of health care resources [4-6]. As a result, a therapy that reduces the development of heart failure after ACS would have considerable health and health economic benefits.

Development of heart failure after an ACS may result from ischemic myocardial injury, and also may reflect longer term progression of underlying coronary atherosclerosis and/or diabetic cardiomyopathy [2]. Patients with diabetes comprise about one third of cases of ACS globally and have an elevated risk of heart failure, with or without concurrent coronary disease [7]. Accordingly, there is an unmet need for new therapies that may be initiated following an ACS to prevent heart failure complications in diabetic patients.

Apabetalone is a selective inhibitor of bromodomain and extra-terminal (BET) proteins. Preclinical studies have implicated BET proteins in the regulation of inflammation, calcification, thrombosis, and lipid and lipoprotein metabolism, all of which participate in atherogenesis [8-12]. Each of these pathways have been shown to be modulated by apabetalone [13-21]. In addition, apabetalone may attenuate the development of cardiac hypertrophy [22] and cardiac fibrosis [23]. A recent Phase 3 clinical trial in patients with type 2 diabetes and recent ACS demonstrated a trend towards fewer ischemic cardiovascular events with apabetalone, compared with placebo [24]. The impact of apabetalone on hospitalization for heart failure, however, has not been evaluated in detail.

\section{Methods}

\section{Study design}

The principal results of the BETonMACE study have been described previously [25]. Eligible patients were at least 18 years of age, had an ACS within the preceding 7-90 days, low HDL cholesterol levels, and a diagnosis of type 2 diabetes. Concomitant treatment with highintensity statin therapy, defined as either atorvastatin $40-80 \mathrm{mg}$ or rosuvastatin $20-40 \mathrm{mg}$ daily, was required. Eligible patients were randomized to treatment with apabetalone $100 \mathrm{mg}$ twice daily or matching placebo. The trial continued until a blinded clinical events committee determined that at least 250 primary events (cardiovascular death, non-fatal myocardial infarction or non-fatal stroke) had occurred. Additional prespecified endpoints measured in the trial included hospitalization for heart failure, including both the first and all subsequent events for each patient.

\section{Statistical analysis}

Baseline characteristics were summarized as percentages for dichotomous data and means (SDs) for approximately normal or medians (IQRs) for non-normal continuous data. Hypothesis test for change in biochemical parameters used ANCOVA models with baseline biomarker value, statin, and country as covariates; results were summarized using least-squares means with $95 \%$ confidence intervals. For non-normal data, a Wilcoxon test was used with results summarized using a Hodges-Lehmann pseudo-median and 95\% bootstrap confidence intervals. The time-to-event analyses used log-rank tests to calculate $\mathrm{P}$-values and Cox proportional hazards model to estimate the hazard ratio (HR) with 95\% confidence interval (CI) and to test for treatment-subgroup interactions. These analyses were stratified by statin and country. Kaplan-Meier curves were also produced. Overall type 1 error control was provided by a sequential gate-keeping procedure that included testing of the primary end point followed by key secondary time-to-event end points. Analyses were performed with SAS software, versions 9.2 or higher (SAS Institute), and R software, version 3.5.1 or higher (R Foundation for Statistical Computing). P-values less than 0.05 were considered statistically significant.

\section{Results}

\section{Clinical characteristics and medication use}

The clinical characteristics of patients are summarized in Table 1. Groups were well balanced by randomization. The median age was 62 years and the majority of patients were male. The index ACS event was myocardial infarction in $75 \%$ of patients and unstable angina in $25 \%$. Nearly four in five patients underwent percutaneous coronary intervention for the index ACS, prior to randomization. All patients had a diagnosis of type 2 diabetes and most had additional risk factors such as hypertension and dyslipidemia. Fifteen percent of patients had a prior clinical history of heart failure, before the index ACS. The median time from presentation with ACS to randomization was 38 days in both treatment groups.

Concomitant medication use is summarized in Table 1. Established cardioprotective therapies for ACS were widely used in both groups, including high-intensity statin and dual anti-platelet therapy, beta-blockers and inhibitors of the renin-angiotensin-aldosterone system. The average duration of diabetes was 8.5 years. The majority of patients were treated with metformin and more than one third with insulin. The use of antidiabetic agents demonstrated to have cardiovascular benefit (SGLT2 inhibitors, GLP1 receptor agonists) was relatively low, consistent with reports of slow uptake of 
Table 1 Baseline patient characteristics and medication use

\begin{tabular}{|c|c|c|}
\hline Characteristic & Placebo $(N=1206)$ & $\begin{array}{l}\text { Apabetalone } \\
(\mathrm{N}=1212)\end{array}$ \\
\hline Age (years) ${ }^{a}$ & $62(56-68)$ & $62(55-68)$ \\
\hline Males (\%) & 74.0 & 74.8 \\
\hline Caucasian (\%) & 87.6 & 87.7 \\
\hline Body mass index $\left(\mathrm{kg} / \mathrm{m}^{2}\right)$ & $30.3 \pm 5.0$ & $30.2 \pm 4.8$ \\
\hline Hypertension (\%) & 87.8 & 89.4 \\
\hline Dyslipidemia (\%) & 75.4 & 74.5 \\
\hline Current or ex-smoker (\%) & 10.4 & 12.1 \\
\hline Duration of diabetes (years) & $8.7 \pm 7.7$ & $84 . \pm 7.6$ \\
\hline Prior myocardial infarction (\%) & 14.7 & 14.4 \\
\hline Prior coronary revascularization (\%) & 21.2 & 21.4 \\
\hline History of heart failure (\%) & 14.8 & 15.1 \\
\hline History of atrial fibrillation (\%) & 7.2 & 7.0 \\
\hline History of chronic kidney disease (\%) & 4.6 & 5.4 \\
\hline \multicolumn{3}{|l|}{ Index ACS event } \\
\hline STEMI (\%) & 39.0 & 38.6 \\
\hline Non-STEMI (\%) & 35.4 & 34.2 \\
\hline Unstable angina (\%) & 25.3 & 26.7 \\
\hline PCl for index ACS (\%) & 79.2 & 79.8 \\
\hline Time from index ACS to randomization (days) ${ }^{a}$ & $38(25-62)$ & $38(25-63.5)$ \\
\hline \multicolumn{3}{|l|}{ Medications } \\
\hline Atorvastatin (\%) & 51.4 & 51.2 \\
\hline Rosuvastatin (\%) & 48.6 & 48.8 \\
\hline High-intensity statin (\%) & 90.5 & 89.9 \\
\hline ACE inhibitor/angiotensin II receptor antagonist (\%) & 92.0 & 92.3 \\
\hline Beta-blockers (\%) & 90.2 & 91.0 \\
\hline Carvedilol, bisoprolol or nebivolol (\%) & 69.1 & 67.6 \\
\hline Anti-platelet agents (\%) & 99.1 & 98.7 \\
\hline Dual anti-platelet agents (\%) & 88.3 & 87.2 \\
\hline Diuretics (\%) & 53.5 & 51.3 \\
\hline Mineralocorticoid receptor antagonists (\%) & 23.1 & 21.8 \\
\hline Sacubitril/valsartan & 0.3 & 0.1 \\
\hline \multicolumn{3}{|l|}{ Diabetes medications } \\
\hline Metformin (\%) & 82.0 & 83.3 \\
\hline Insulin (\%) & 38.5 & 36.7 \\
\hline Sulfonlyureas (\%) & 28.5 & 30.0 \\
\hline DPP4 inhibitors (\%) & 14.8 & 14.9 \\
\hline SGLT2 inhibitors (\%) & 12.3 & 12.4 \\
\hline GLP1 receptor agonists (\%) & 3.7 & 3.4 \\
\hline
\end{tabular}

Clinical characteristics and medication use of patients treated with apabetalone or placebo. Results expressed as percentage, mean \pm standard deviation or ${ }^{a}$ median (interquartile range)

ACS acute coronary syndrome, DPP4 dipeptidyl peptidase 4, GLP1 glucagon like peptide 1, PCl percutaneous coronary intervention, SGLT2 sodium glucose transporter 2, STEMI ST segment myocardial infarction

these agents in the clinical management of diabetic ACS patients.

\section{Biochemical parameters}

Biochemical parameters and their change after 24 weeks of treatment with placebo and apabetalone are summarized in Table 2. Consistent with the use of highintensity statin at randomization, the average LDL-C was $70 \mathrm{mg} / \mathrm{dL}$, while the median hsCRP was $2.8 \mathrm{mg} / \mathrm{L}$. Consistent with prior observations, apabetalone-treated patients demonstrated increase in HDL cholesterol and decrease in alkaline phosphatase, compared with 
Table 2 Biochemistry

\begin{tabular}{|c|c|c|c|}
\hline Parameter & Placebo & Apabetalone & P value \\
\hline \multicolumn{4}{|l|}{$\mathrm{HbA1c}$} \\
\hline Baseline (\%) & $7.3(6.4-8.6)$ & $7.4(6.4-8.7)$ & \\
\hline Follow up (\%) & $7.2(6.4-8.4)$ & $7.2(6.4-8.5)$ & \\
\hline Absolute change (\%) & $0.00[-0.10,0.05]$ & $-0.05[-0.15,0.00]$ & 0.18 \\
\hline Percent change (\%) & $0.04[-0.76,0.88]$ & $-0.63[-1.49,0.25]$ & 0.25 \\
\hline \multicolumn{4}{|l|}{ LDL-C } \\
\hline Baseline (mg/dL) & $70.9 \pm 32.4$ & $69.7 \pm 29.8$ & \\
\hline Follow up (mg/dL) & $63.6 \pm 29.4$ & $63.4 \pm 28.3$ & \\
\hline Absolute change (mg/dL) & $-6.55[-8.00,-5.10]$ & $-6.34[-7.79,-4.89]$ & 0.37 \\
\hline Percent change (\%) & $-0.31[-4.13,3.50]$ & $-1.57[-2.25,5.38]$ & 0.28 \\
\hline \multicolumn{4}{|l|}{$\mathrm{HDL}-\mathrm{C}$} \\
\hline Baseline (mg/dL) & $33.3 \pm 5.1$ & $33.3 \pm 5.1$ & \\
\hline Follow up (mg/dL) & $36.6 \pm 7.5$ & $38.0 \pm 8.0$ & \\
\hline Absolute change (mg/dL) & $3.34[2.93,3.75]$ & $4.75[4.34,5.15]$ & $<0.0001$ \\
\hline Percent change (\%) & $10.9[9.62,12.2]$ & $15.4[14.1,16.7]$ & $<0.0001$ \\
\hline \multicolumn{4}{|l|}{ hsCRP } \\
\hline Baseline (mg/L) & $2.7(1.1-6.1)$ & $2.9(1.3-5.9)$ & \\
\hline Follow up (mg/L) & $1.8(1.0-4.3)$ & $1.8(0.9-3.9)$ & \\
\hline Absolute change (mg/L) & $-0.53[-0.93,-0.24]$ & $-0.80[-1.3,-0.44]$ & 0.34 \\
\hline Percent change (\%) & $-11.3[-20.0,-1.5]$ & $-18.4[-28.0,-7.1]$ & 0.16 \\
\hline \multicolumn{4}{|l|}{ ALP } \\
\hline Baseline (U/L) & $81.9 \pm 34.7$ & $83.3 \pm 38.2$ & \\
\hline Follow up $(U / L)$ & $79.5 \pm 29.5$ & $74.3 \pm 43.2$ & \\
\hline Absolute change (U/L) & $-2.20[-3.60,-0.81]$ & $-8.98[-10.4,-7.59]$ & $<0.0001$ \\
\hline Percent change (\%) & $4.22[0.27,8.18]$ & $-8.31[-12.2,-4.37]$ & $<0.0001$ \\
\hline \multicolumn{4}{|l|}{ eGFR } \\
\hline Baseline (mL/min) & $102 \pm 38.6$ & $105 \pm 39.2$ & \\
\hline Follow up (mL/min) & $105 \pm 40.2$ & $106 \pm 41.9$ & \\
\hline Absolute change $(\mathrm{mL} / \mathrm{min})$ & $2.02[0.97,3.07]$ & $-0.33[-1.38,1.72]$ & 0.001 \\
\hline Percent change (\%) & $3.03[1.87,4.18]$ & $-0.46[-0.70,1.61]$ & 0.001 \\
\hline
\end{tabular}

Biochemical parameters at baseline and change after 24 weeks (12 weeks for CRP) of treatment with apabetalone or placebo. Baseline means \pm SDs or medians (IQR) are shown. For absolute and percent change, estimates with $[95 \% \mathrm{Cls}]$ are given

$A L P$ alkaline phosphatase, $H b A 1 c$ glycated haemoglobin, $H D L-C$ high-density lipoprotein cholesterol, $h$ s CRP high-sensitivity $C$-reactive protein (assessed in only a subset of patients), LDL-C low-density lipoprotein cholesterol, eGFR estimated glomerular filtration rate

placebo. In addition, no significant reduction in estimated glomerular filtration rate was observed in the apabetalone group.

\section{Hospital admissions for heart failure}

The incidence of cardiovascular events during the trial are summarized in Table 3. Apabetalone-treated patients experienced a lower rate of first $[2.4 \%$ vs. $4.0 \%, \mathrm{HR}=0.59(0.38-0.94), \mathrm{P}=0.03]$ and total (35 vs. $70, \mathrm{P}=0.01$ ) hospital admissions for heart failure. Of the 105 total hospital admissions for heart failure, 53 (50.5\%) occurred in patients with a known history of heart failure prior to study entry (assessed through a general medical history questionnaire rather than a prospective question) and 27 (25.7\%) occurred in patients following an acute coronary syndrome during the study. In a post-hoc sensitivity analysis of those with no known history of heart failure, the effect of apabetalone on first hospital admissions for heart failure showed a similar hazard ratio, though the overall rates in both treatment arms were lower as might be expected $[1.5 \%$ vs. $2.6 \%, \mathrm{HR}=0.56(0.30-1.05)]$. The combination of either first hospital admission for heart failure or cardiovascular death occurred less frequently in apabetalone than placebo-treated patients $(5.7 \%$ vs. $7.8 \%, \mathrm{P}=0.04$ for all patients, $3.8 \%$ vs. $5.7 \%$ for those with no known history of heart failure), with qualitative evidence of an early and progressive separation in 
Table 3 Clinical events

\begin{tabular}{|c|c|c|c|}
\hline Parameter & Placebo $(\mathrm{N}=1206)$ & Apabetalone $(\mathrm{N}=1212)$ & $P$ value \\
\hline First hospitalization for heart failure, n (\%) & $48(4.0)$ & $29(2.4)$ & 0.03 \\
\hline $\mathrm{HR}(95 \% \mathrm{Cl})$ & $0.59(0.38-0.94)$ & & \\
\hline Total hospitalizations for heart failure, n & 70 & 35 & 0.01 \\
\hline $\mathrm{HR}(95 \% \mathrm{Cl})$ & $0.47(0.27-0.83)$ & & \\
\hline Cardiovascular death, n (\%) & $55(4.6)$ & $45(3.7)$ & 0.28 \\
\hline $\mathrm{HR}(95 \% \mathrm{Cl})$ & $0.81(0.54-1.19)$ & & \\
\hline $\begin{array}{l}\text { First hospitalization for heart failure or cardiovascular death, } \\
n(\%)\end{array}$ & $94(7.8)$ & $69(5.7)$ & 0.04 \\
\hline $\mathrm{HR}(95 \% \mathrm{Cl})$ & $0.72(0.53-0.98)$ & & \\
\hline
\end{tabular}

Cardiovascular events in patients treated with apabetalone or placebo

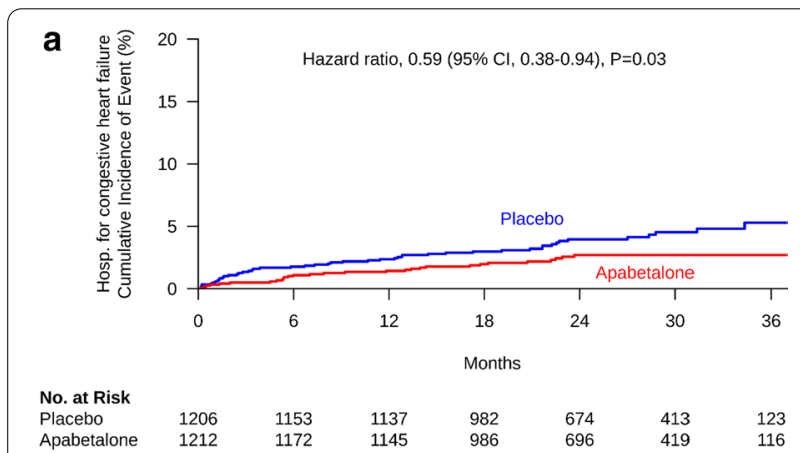

b

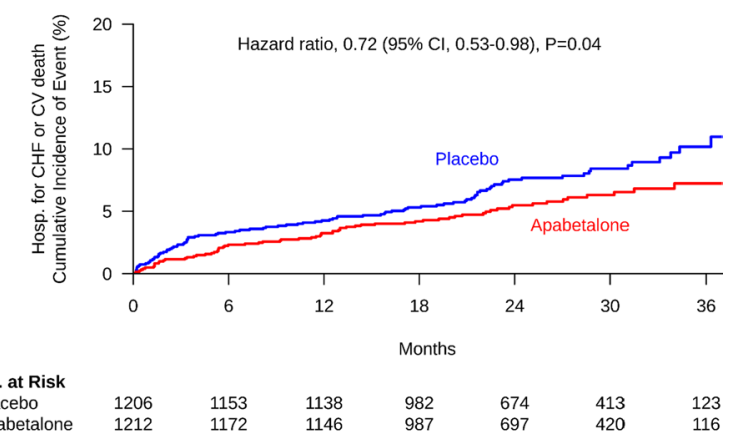

Fig. 1 Hospitalization for heart failure. Incidence of first hospital admission for heart failure (a) or the combination of first hospital admission for heart failure or cardiovascular death (b) in patients treated with apabetalone or placebo

events (Fig. 1). Since a sequential gate-keeping procedure was used to control overall type 1 error and the primary outcome for BETonMACE was not significant, these P-values should be interpreted with caution.

Subgroup analysis revealed a consistent effect of apabetalone on hospitalization for heart failure (Fig. 2). Of note, benefit appeared to be independent of sex, lipid profile components, glycemic status, age, and renal function.

\section{Discussion}

The BETonMACE study was the first Phase 3 clinical trial to evaluate the cardiovascular efficacy and safety of a selective BET protein inhibitor, intended to modulate epigenetic factors implicated in cardiovascular disease [26]. The primary analysis of the trial demonstrated a trend towards fewer cardiovascular deaths, non-fatal myocardial infarctions and strokes, although this failed to meet statistical significance [24]. In the current, prespecified analysis, we observed that treatment with apabetalone following an ACS was associated with a lower incidence of hospital admission for heart failure. This finding points to a potentially important clinical benefit of treatment with apabetalone in patients with recent ACS.

The development of heart failure, regardless of the underlying etiology or left ventricular systolic function, typically portends a poor prognosis [4-6]. Such patients enter a deteriorating cycle, characterized by frequent hospital admissions, deteriorating quality of life, an increased risk of death, and substantial health care costs. Randomized controlled trials in patients with chronic heart failure have demonstrated benefit of several interventions such as beta-adrenergic receptor blockade or inhibitors of the renin-angiotensin-aldosterone system $[27,28]$. However, there is also a need for therapies that reduce incident heart failure, above and beyond conventional strategies such as blood pressure control or prevention of myocardial infarction with antiplatelet agents or statins. Clinical registries have reported that many patients develop clinically significant heart failure in the first 12 months following an ACS, regardless of the presence of heart failure prior to the index ACS event $[2,3]$. When heart failure occurs after ACS, it often requires hospital admission and is associated with an increased risk of death [4-6]. While $15 \%$ of patients in BETonMACE reported a prior clinical history of heart failure, the benefit of apabetalone did not appear to be limited 


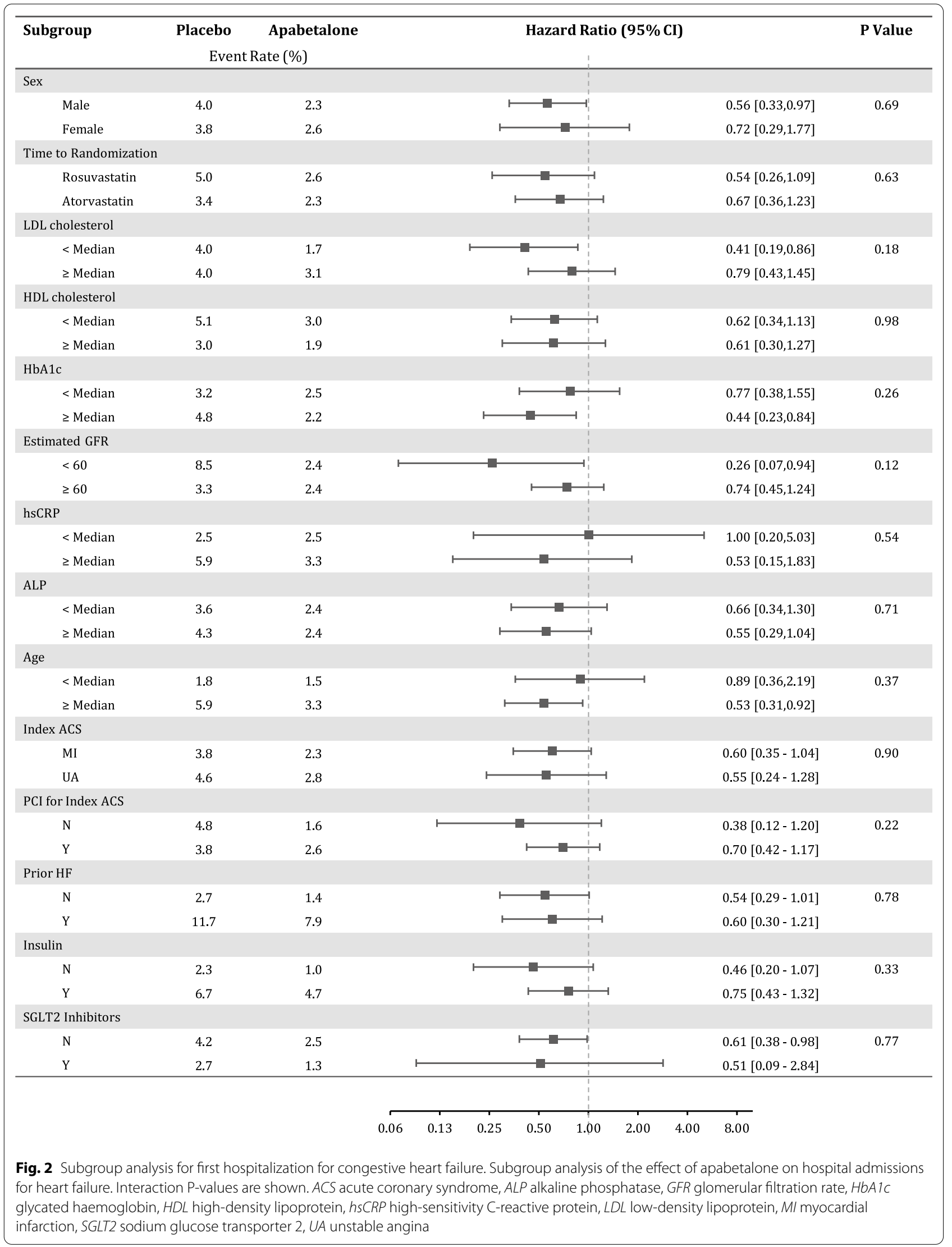


to this group. An agent that reduces the risk of incident heart failure would have the potential to improve the prognosis following ACS.

The present observations indicating that apabetalone reduces the risk of hospital admission for heart failure following an ACS is supported by preclinical studies that link BET proteins to a range of mediators of heart failure [8-12]. In those studies, apabetalone favorably modulated immune, oxidative, fibrotic, hypertrophic and vascular calcification pathways implicated in the genesis of both atherosclerosis and heart failure, as evidenced by gene and protein expression profiling in cell studies [13-23]. Other BET inhibitors have also been shown to reduce cardiomyocyte hypertrophy, myocardial fibrosis and apoptosis, in parallel with favorable effects on gene expression [22, 29-32]. These data from BETonMACE suggest that such cellular effects of BET inhibition may translate into clinical benefit for reducing heart failure risk.

Several limitations of the present analysis are recognized. First, neither measures of cardiac function nor circulating biomarkers (e.g., brain natriuretic peptide) associated with heart failure were collected systematically. Such measurements would have identified patients with subclinical cardiac dysfunction, and may have provided insight as to whether or not those patients derived the greatest benefit from apabetalone. Accordingly, we could not make a distinction between heart failure in the setting of preserved or reduced ejection fraction. Second, although hospitalization for heart failure was a prespecified end point in the BETonMACE trial [26], the potential effect of apabetalone on cardiovascular death, myocardial infarction, or stroke, the primary endpoint of the trial, failed to meet statistical significance [24]. As a result, the observation of a favorable effect on a secondary endpoint should be considered an exploratory finding. Third, the study was performed exclusively in patients with type 2 diabetes, a group of patients known to be at high risk of both recurrent ischemic events after ACS and heart failure per se. Whether similar findings would be observed in a broader ACS cohort is unknown. Fourth, the benefit of apabetalone on heart failure events was observed on a background of high utilization of beta-blockers and renin-angiotensin system inhibitors, agents demonstrated to be beneficial in heart failure $[27,28]$. However, there was little background use of SGLT2 inhibitors, another class reported to reduce heart failure events [33, 34], although potential efficacy in the post ACS setting has not been established. Fifth, a prior history of heart failure was collected by voluntary patient reporting, limiting the ability to investigate the impact of apabetalone in patients with established heart failure in the current analysis. Finally, given that the primary endpoint of the
BETonMACE study did not meet statistical significance, the current findings should be considered nominal.

\section{Conclusion}

In summary, use of the selective BET inhibitor, apabetalone was associated with a lower rate of hospital admissions for heart failure in patients with type 2 diabetes and recent ACS. The mechanism underlying this potential benefit remains uncertain and requires further investigation. If this finding is replicated in future clinical trials, it may provide an important new therapeutic strategy to modulate the high rate of both atherothrombotic and heart failure-related complications following an ACS in patients with diabetes.

\section{Abbreviations \\ ACS: Acute coronary syndrome; BET: Bromodomain and extra-terminal; $\mathrm{Cl}$ : Confidence interval; GLP-1: Glucagon like peptide-1; HbA1c: Glycated hemo- globin; HDL-C: High-density lipoprotein cholesterol; HR: Hazard ratio; hsCRP: High sensitivity C-reactive protein; LDL-C: Low-density lipoprotein choles- terol; MACE: Major adverse cardiovascular events; SGLT2: Sodium glucose transporter 2.}

\section{Acknowledgements}

Not applicable.

\section{Authors' contributions}

KKR, SJN, GGS, HNG, KK-Z and PPT were academic members of the steering committee who designed the study protocol and provided academic leadership of BETonMACE in collaboration with the sponsor, who were represented by JOJ, EK, NW and MS. SJN led this analysis and drafted the manuscript. KAB performed all statistical analyses for the manuscript. All authors read and approved the final manuscript.

\section{Funding}

The BETOnMACE was sponsored by Resverlogix.

\section{Availability of data and materials}

The data that support the findings of this study are available from Resverlogix but restrictions apply to the availability of these data, which were used under license for the current study, and so are not publicly available. Data are however available from the authors upon reasonable request and with permission of Resverlogix.

\section{Ethics approval and consent to participate}

This is a subsequent analysis of a multicenter clinical trial. All sites required local ethics committee approval prior to study initiation and all participating patients provided informed, written consent.

\section{Consent for publication}

Not applicable.

\section{Competing interests}

SJN reports research grants from AstraZeneca, Amgen, Anthera, Eli Lilly, Esperion, Novartis, Cerenis, The Medicines Company, Resverlogix, InfraReDx, Roche, Sanofi-Regeneron and LipoScience and honoraria from AstraZeneca, Akcea, Eli Lilly, Anthera, Omthera, Merck, Takeda, Resverlogix, Sanofi-Regeneron, CSL Behring, Esperion, Boehringer Ingelheim. GGS reports grants to his institution from Resverlogix, Roche, Sanofi and The Medicines Company. GGS also has a pending patent US 62/806,313 "Methods for Reducing Cardiovascular Risk" assigned in full to the University of Colorado. KAB reports research grants from Resverlogix, The Medicines Company, GlaxoSmithKline, Pfizer, BioCardia, Amgen and Cytokinetics. HNG reports honoraria from Resverlogix. JOJ, EK, NW and MS are employees of Resverlogix. KK-Z reports honoraria from Abbott, Abbvie, Alexion, Amgen, AstraZeneca, Aveo, Chugai, DaVita, Fresenius Medical 
Services, Genentech, Haymarket, Hospira, Kabi, Keryx, Novartis, Pfizer, Relypsa, Resverlogix, Sandoz, Sanofi, Vifor, ZS-Pharma, UpToDate, Baxter, Dr Schaer, Amag Pharma and grants from Shire, PCORI and NIH. PPT reports honoraria from Resverlogix, Amarin, Amgen, Kowa, Merck, Novo-Nordisk, Regeneron, Sanofi, Theravance. KKR reports honoraria from Resverlogix, Aegerion, Amgen, Pfizer, AstraZeneca, Cerenis, Akcea, The Medicines Company, Kowa, Novartis, Cipla, Eli Lilly, Algorithm, Takeda, Boehringer Ingelheim, Abbvie, Silence Therapeutics, Dr Reddys, Bayer, Daiichi Sankyo, Esperion, Zuelling Pharma, SanofiRegeneron and Merck and grants from Sanofi-Regeneron and Merck.

\section{Author details}

${ }^{1}$ Monash Cardiovascular Research Centre, Monash University, 246 Clayton Road, Clayton, VIC 3168, Australia. ${ }^{2}$ Division of Cardiology, University of Colorado School of Medicine, Aurora, CO, USA. ${ }^{3}$ Statistical Data Analysis Center, University of Wisconsin-Madison, Madison, WI, USA. ${ }^{4}$ Irving Institute for Clinical and Translational Research, Columbia University, New York, NY, USA. ${ }^{5}$ Resverlogix Corporation, Calgary, AB, Canada. ${ }^{6}$ Division of Nephrology and Hypertension, University of California Irvine, Irvine, USA. ${ }^{7}$ CGH Medical Center Sterling, Sterling, IL, USA. ${ }^{8}$ Cicarrone Center for the Prevention of Cardiovascular Disease, Johns Hopkins University School of Medicine, Baltimore, MD, USA. ${ }^{9}$ Imperial Centre for Cardiovascular Disease Prevention, Imperial College, London, UK.

Received: 15 September 2020 Accepted: 17 December 2020 Published online: 07 January 2021

\section{References}

1. Dunlay SM, Givertz MM, Aguilar D, Allen LA, Chan M, Desai AS, Deswal A, Dickson W, Kosiborod MN, Lekavich CL, McCoy RG, Mentz RJ, Pina IL, American Heart Association Heart F, Transplantation Committee of the Council on Clinical C, Council on C, Stroke N and the Heart Failure Society of A. Type 2 Diabetes Mellitus and Heart Failure: A Scientific Statement From the American Heart Association and the Heart Failure Society of America: This statement does not represent an update of the 2017 ACC/AHA/HFSA heart failure guideline update. Circulation. 2019;140:e294-324.

2. Cahill TJ, Kharbanda RK. Heart failure after myocardial infarction in the era of primary percutaneous coronary intervention: Mechanisms, incidence and identification of patients at risk. World J Cardiol. 2017;9:407-15.

3. Torabi A, Cleland JG, Rigby AS, Sherwi N. Development and course of heart failure after a myocardial infarction in younger and older people. J Geriatr Cardiol. 2014;11:1-12.

4. Shah KS, Xu H, Matsouaka RA, Bhatt DL, Heidenreich PA, Hernandez AF, Devore AD, Yancy CW, Fonarow GC. Heart failure with preserved, borderline, and reduced ejection fraction: 5-year outcomes. J Am Coll Cardiol. 2017;70:2476-86.

5. Bash LD, Weitzman D, Blaustein RO, Sharon O, Shalev V, Chodick G. Comprehensive healthcare resource use among newly diagnosed congestive heart failure. Isr J Health Policy Res. 2017;6:26.

6. Echouffo-Tcheugui JB, Bishu KG, Fonarow GC, Egede LE. Trends in health care expenditure among US adults with heart failure: the medical expenditure panel survey 2002-2011. Am Heart J. 2017;186:63-72.

7. Einarson TR, Acs A, Ludwig C, Panton UH. Prevalence of cardiovascular disease in type 2 diabetes: a systematic literature review of scientific evidence from across the world in 2007-2017. Cardiovasc Diabetol. 2018;17:83.

8. Huang B, Yang XD, Zhou MM, Ozato K, Chen LF. Brd4 coactivates transcriptional activation of NF-kappaB via specific binding to acetylated RelA. Mol Cell Biol. 2009;29:1375-87.

9. Nicodeme E, Jeffrey KL, Schaefer U, Beinke S, Dewell S, Chung CW, Chandwani R, Marazzi I, Wilson P, Coste H, White J, Kirilovsky J, Rice CM, Lora JM, Prinjha RK, Lee K, Tarakhovsky A. Suppression of inflammation by a synthetic histone mimic. Nature. 2010;468:1119-23.

10. Brown JD, Lin CY, Duan Q, Griffin G, Federation A, Paranal RM, Bair S, Newton G, Lichtman A, Kung A, Yang T, Wang H, Luscinskas FW, Croce K, Bradner JE, Plutzky J. NF-kappaB directs dynamic super enhancer formation in inflammation and atherogenesis. Mol Cell. 2014;56:219-31.
11. Das S, Senapati P, Chen Z, Reddy MA, Ganguly R, Lanting L, Mandi V, Bansal A, Leung A, Zhang S, Jia Y, Wu X, Schones DE, Natarajan R. Regulation of angiotensin II actions by enhancers and super-enhancers in vascular smooth muscle cells. Nat Commun. 2017:8:1467.

12. Dey A, Yang W, Gegonne A, Nishiyama A, Pan R, Yagi R, Grinberg A, Finkelman FD, Pfeifer K, Zhu J, Singer D, Zhu J, Ozato K. BRD4 directs hematopoietic stem cell development and modulates macrophage inflammatory responses. EMBO J. 2019;38:e100293.

13. Bailey D, Jahagirdar R, Gordon A, Hafiane A, Campbell S, Chatur S, Wagner GS, Hansen HC, Chiacchia FS, Johansson J, Krimbou L, Wong NC, Genest J. RVX-208: a small molecule that increases apolipoprotein A-I and highdensity lipoprotein cholesterol in vitro and in vivo. J Am Coll Cardiol. 2010;55:2580-9.

14. McLure KG, Gesner EM, Tsujikawa L, Kharenko OA, Attwell S, Campeau E, Wasiak S, Stein A, White A, Fontano E, Suto RK, Wong NC, Wagner GS, Hansen HC, Young PR. RVX-208, an inducer of ApoA-I in humans, is a BET bromodomain antagonist. PLoS ONE. 2013;8:e83190.

15. Picaud S, Wells C, Felletar I, Brotherton D, Martin S, Savitsky P, Diez-Dacal B, Philpott M, Bountra C, Lingard H, Fedorov O, Muller S, Brennan PE, Knapp S, Filippakopoulos P. RVX-208, an inhibitor of BET transcriptional regulators with selectivity for the second bromodomain. Proc Natl Acad Sci USA. 2013;110:19754-9.

16. Jahagirdar R, Zhang H, Azhar S, Tobin J, Attwell S, Yu R, Wu J, McLure KG, Hansen HC, Wagner GS, Young PR, Srivastava RA, Wong NC, Johansson J. A novel BET bromodomain inhibitor, RVX-208, shows reduction of atherosclerosis in hyperlipidemic ApoE deficient mice. Atherosclerosis. 2014;236:91-100.

17. Gilham D, Wasiak S, Tsujikawa LM, Halliday C, Norek K, Patel RG, Kulikowski E, Johansson J, Sweeney M, Wong NC, Gordon A, McLure K, Young P. RVX208, a BET-inhibitor for treating atherosclerotic cardiovascular disease, raises ApoA-1/HDL and represses pathways that contribute to cardiovascular disease. Atherosclerosis. 2016;247:48-57.

18. Wasiak S, Gilham D, Tsujikawa LM, Halliday C, Norek K, Patel RG, McLure KG, Young PR, Gordon A, Kulikowski E, Johansson J, Sweeney M, Wong NC. Data on gene and protein expression changes induced by apabetalone (RVX-208) in ex vivo treated human whole blood and primary hepatocytes. Data Brief. 2016:8:1280-8.

19. Wasiak S, Gilham D, Tsujikawa LM, Halliday C, Calosing C, Jahagirdar R, Johansson J, Sweeney M, Wong NC, Kulikowski E. Downregulation of the complement cascade in vitro, in mice and in patients with cardiovascular disease by the BET protein inhibitor apabetalone (RVX-208). J CardiovasC Transl Res. 2017;10:337-47.

20. Gilham D, Tsujikawa LM, Sarsons CD, Halliday C, Wasiak S, Stotz SC, Jahagirdar R, Sweeney M, Johansson JO, Wong NCW, Kalantar-Zadeh K, Kulikowski E. Apabetalone downregulates factors and pathways associated with vascular calcification. Atherosclerosis. 2019;280:75-84.

21. Tsujikawa LM, Fu L, Das S, Halliday C, Rakai BD, Stotz SC, Sarsons CD, Gilham D, Daze E, Wasiak S, Studer D, Rinker KD, Sweeney M, Johansson JO, Wong NCW, Kulikowski E. Apabetalone (RVX-208) reduces vascular inflammation in vitro and in CVD patients by a BET-dependent epigenetic mechanism. Clin Epigenet. 2019;11:102.

22. Anand P, Brown JD, Lin CY, Qi J, Zhang R, Artero PC, Alaiti MA, Bullard J, Alazem K, Margulies KB, Cappola TP, Lemieux M, Plutzky J, Bradner JE, Haldar SM. BET bromodomains mediate transcriptional pause release in heart failure. Cell. 2013;154:569-82.

23. Song S, Liu L, Yu Y, Zhang R, Li Y, Cao W, Xiao Y, Fang G, Li Z, Wang X, Wang Q, Zhao X, Chen L, Wang Y, Wang Q. Inhibition of BRD4 attenuates transverse aortic constriction- and TGF-beta-induced endothelial-mesenchymal transition and cardiac fibrosis. J Mol Cell Cardiol. 2019;127:83-96.

24. Ray KK, Nicholls SJ, Ginsberg HN, Johansson JO, Kalantar-Zadeh K, Kulikowski E, Toth PP, Wong N, Sweeney M, Schwartz GG. Effect of BET protein inhibition with apabetalone on cardiovascular outcomes in patients with acute coronary syndrome and diabetes-results of the BETonMACE trial. Circulation. 2019;140:e965-1011.

25. Ray KK, Nicholls SJ, Buhr KA, Ginsberg HN, Johansson JO, Kalantar-Zadeh K, Kulikowski E, Toth PP, Wong N, Sweeney M, Schwartz GG, Investigators $\mathrm{BE}$ and Committees. Effect of apabetalone added to standard therapy on major adverse cardiovascular events in patients with recent acute coronary syndrome and type 2 diabetes: a randomized clinical trial. JAMA. 2020;323:1565-73. 
26. Ray KK, Nicholls SJ, Ginsberg HD, Johansson JO, Kalantar-Zadeh K, Kulikowski E, Toth PP, Wong N, Cummings JL, Sweeney M, Schwartz GG. Effect of selective BET protein inhibitor apabetalone on cardiovascular outcomes in patients with acute coronary syndrome and diabetes: Rationale, design, and baseline characteristics of the BETonMACE trial. Am Heart J. 2019;217:72-83.

27. Martin N, Manoharan K, Thomas J, Davies C, Lumbers RT. Beta-blockers and inhibitors of the renin-angiotensin aldosterone system for chronic heart failure with preserved ejection fraction. Cochrane Database Syst Rev. 2018;6:CD012721.

28. Feng J-L, Qin X. Association between evidence-based medication at discharge and outcomes in patients with heart failure: a systematic review and meta-analysis. Heart Failure Rev. 2019. https://doi.org/10.1007/s1074 1-019-09900-3.

29. Duan Q, McMahon S, Anand P, Shah H, Thomas S, Salunga HT, Huang Y, Zhang R, Sahadevan A, Lemieux ME, Brown JD, Srivastava D, Bradner JE, McKinsey TA, Haldar SM. BET bromodomain inhibition suppresses innate inflammatory and profibrotic transcriptional networks in heart failure. Sci Transl Med. 2017;9:eaah5084.

30. Stratton MS, Lin CY, Anand P, Tatman PD, Ferguson BS, Wickers ST, Ambardekar AV, Sucharov CC, Bradner JE, Haldar SM, McKinsey TA. Signaldependent recruitment of BRD4 to cardiomyocyte super-enhancers is suppressed by a MicroRNA. Cell Rep. 2016;16:1366-78.

31. Stratton MS, Bagchi RA, Felisbino MB, Hirsch RA, Smith HE, Riching AS, Enyart BY, Koch KA, Cavasin MA, Alexanian M, Song K, Qi J, Lemieux ME,
Srivastava D, Lam MPY, Haldar SM, Lin CY, McKinsey TA. Dynamic chromatin targeting of BRD4 stimulates cardiac fibroblast activation. Circ Res. 2019;125:662-77.

32. Spiltoir Jl, Stratton MS, Cavasin MA, Demos-Davies K, Reid BG, Qi J, Bradner JE, McKinsey TA. BET acetyl-lysine binding proteins control pathological cardiac hypertrophy. J Mol Cell Cardiol. 2013;63:175-9.

33. Lytvyn Y, Bjornstad P, Udell JA, Lovshin JA, Cherney DZI. Sodium glucose cotransporter-2 inhibition in heart failure: potential mechanisms, clinical applications, and summary of clinical trials. Circulation. 2017;136:1643-58.

34. McMurray JJV, Solomon SD, Inzucchi SE, Kober L, Kosiborod MN, Martinez FA, Ponikowski P, Sabatine MS, Anand IS, Belohlavek J, Bohm M, Chiang CE, Chopra VK, de Boer RA, Desai AS, Diez M, Drozdz J, Dukat A, Ge J, Howlett JG, Katova T, Kitakaze M, Ljungman CEA, Merkely B, Nicolau JC, O'Meara E, Petrie MC, Vinh PN, Schou M, Tereshchenko S, Verma S, Held C, DeMets DL, Docherty KF, Jhund PS, Bengtsson O, Sjostrand M, Langkilde AM, Committees D-HT and Investigators. Dapagliflozin in patients with heart failure and reduced ejection fraction. N Engl J Med. 2019;381:1995-2008.

\section{Publisher's Note}

Springer Nature remains neutral with regard to jurisdictional claims in published maps and institutional affiliations.
Ready to submit your research? Choose BMC and benefit from:

- fast, convenient online submission

- thorough peer review by experienced researchers in your field

- rapid publication on acceptance

- support for research data, including large and complex data types

- gold Open Access which fosters wider collaboration and increased citations

- maximum visibility for your research: over 100M website views per year

At BMC, research is always in progress.

Learn more biomedcentral.com/submissions 